\title{
Lung biopsy with the high speed drill in a developing country
}

\author{
BAYU TEKLU
}

From the Department of Medicine, Tikur Anbessa Hospital, Addis Ababa University Medical Faculty, Addis Ababa, Ethiopia

ABSTRACT The results of high speed air drill lung biopsy during 38 months in Addis Ababa is reported. Even though the diagnostic yield was only $49 \%$, trephine lung biopsy has a place in theo investigation of diffuse and accessible localised lesions of the lung. It has proved to be a relativelyp safe and simple procedure. Nineteen male and 20 female patients were studied and in addition eigh? postmortem specimens of lung tissue were included. The chest radiograph showed diffuse pul $\overrightarrow{-}$ monary infiltrates in 42 and localised in six, with diagnostic biopsy specimens in 20 and fives respectively. Biopsy of the inferior lung in the lateral decubitus position in patients with diffuse lungf lesions has yielded larger specimens than has routine biopsy performed in the sitting position. Sincethe only patient who developed appreciable haemoptysis was the single patient with chronic coro pulmonale, caution should be exercised in such cases. A chest radiograph is indicated after biopsyo only when the clinical condition of the patient warrants it.

Steel's trephine has been used for biopsy of both diffuse and localised lesions of the lung for over two decades. Several investigators have found the procedure satisfactory, ${ }^{1-3}$ while others have not. ${ }^{4}$ The trephine biopsy is superior to aspiration needle biopsy, introduced almost four decades ago. ${ }^{5}$ The Vim-Silverman, Franklin-Silverman, and Jack needles produced very small fragments of tissue, which were usually inadequate for interpretation and the procedure was occasionally complicated by death. ${ }^{6-8}$ Recently, however, Trucut lung biopsy, using a different technique, has proved to be very useful. ${ }^{9}$

In developing countries such as Ethiopia, where there is an extreme shortage of surgeons and resources, high speed drill lung biopsy offers a simple and inexpensive alternative to thoracotomy in the diagnosis of diffuse and localised peripheral lung lesions. Upper lobe lesions and those near the mediastinum are best avoided. This report documents 38 months' experience of trephine biopsy of the lung (from July 1982 to August 1985) in Addis Ababa. I am not aware of any other report of its use from Africa.

Address for reprint requests: Dr B Teklu, Division of Respiratory Diseases (RM-12), University Hospital, University of Washington, 1959 NE Pacific Street, Seattle, Washington 98195, USA.

Accepted 1 April 1986

\section{Methods}

Patients with accessible localised lesions in the mid of lower lung zones or diffuse lung lesions undiagnoseç by sputum examination, or in some cases by bron? choscopy, were subjected to trephine biopsy.

The technique of trephine biopsy of the lung described by Steel ${ }^{10}$ was modified in this study Firstly, routine thin needle aspiration of homoge neous masses was performed before biopsy to make sure that they were not fluid collections. Secondly, in. patients who were too weak to sit, biopsy was takerin from the inferior lung in the decubitus position Thirdly, a $20 \mathrm{ml}$ syringe was half filled with norma saline instead of citrate solution to suck up the biopsy specimen when the trephine was withdrawn. Fourth routine chest radiographs were not taken after the procedure.

Fifty one trephine biopsy attempts were made in $3 \dot{Q}$ patients. Eight of the samples were obtained poste mortem. The biopsies were studied only histologically as a mycobacterial laboratory was not readily avail able.

\section{Results}

There were 19 male and 20 female patients, aged 17-74 years. The mean age of the men was 45.7 and of the women 45. Results of biopsies are shown in table 1. Twenty five $(49 \%)$ of the biopsies were diagnostic? 
Table 1 Histological diagnosis in 47 trephine biopsies

\begin{tabular}{|c|c|c|c|}
\hline \multirow[b]{2}{*}{ Histological type } & \multicolumn{3}{|c|}{ Radiographic lesion } \\
\hline & Diffuse & Localised & Total \\
\hline \multicolumn{4}{|l|}{ Diagnostic } \\
\hline Pulmonary fibrosis & 9 & - & 9 \\
\hline Primary lung cancer & 4 & - & 4 \\
\hline Acute inflammation (pneumonia) & - & 2 & 2 \\
\hline Chronic inflammation & 2 & 1 & 3 \\
\hline Tuberculosis & 5 & - & 5 \\
\hline Secondary carcinoma & - & 2 & 2 \\
\hline Total & 20 & 5 & 25 \\
\hline \multicolumn{4}{|l|}{ Non-diagnostic } \\
\hline Normal & 8 & - & 8 \\
\hline Inadequate/no lung & 9 & 1 & 10 \\
\hline Liver tissue only & 4 & - & 4 \\
\hline Total & 21 & 1 & 22 \\
\hline
\end{tabular}

Pulmonary fibrosis was the most common histological diagnosis, followed by tuberculosis. There were two squamous carcinomas, one adenocarcinoma, and one bronchoalveolar carcinoma. The secondary carcinomas were hepatoma and fibrosarcoma. Eight $(15 \%)$ of biopsies showed normal lung, although diffuse lung infiltrates were seen radiographically. Nine $(17 \%)$ of biopsy specimens either were inadequate for interpretation or had no lung tissue. In five patients liver tissue was obtained inadvertently and in one of them lung tissue was obtained simultaneously. Histological examination of the liver specimens showed two normal, one fatty and one cirrhotic liver and one hepatoma.

Although several attempts at chest aspiration in three patients were unsuccessful in obtaining fluid, thick pus was obtained in two patients and clear fluid in another by means of the trephine. In one of the patients the fluid suggested a diagnosis of hydatid cyst, and this was subsequently confirmed at thoracotomy.

In the eight cases in which lung specimens were obtained postmortem the chest radiograph showed a localised lesion in five and diffuse disease in two. The remaining patient suffered from asthma and had a normal chest radiograph; histological appearances were normal, although the specimen contained no bronchi. Biopsy specimens from the localised lesions showed pneumonia in two, normal lung in two (one of them had liver tissue also), and cirrhosis of the liver in one. The specimens from two individuals with diffuse disease showed pulmonary fibrosis.

Most of the biopsy specimens obtained from patients with diffuse pulmonary shadows were small fragments of tissue. Biopsy of the inferior lung in the decubitus position, however, gave uniformly good samples in patients who could not sit up for the biopsy. Specimens from the solid localised lesions were also satisfactory.
After the biopsy, blood pressure and pulse were measured regularly for six hours and close observation for the development of shortness of breath was maintained for 24 hours. Although pneumothoraces were detected on physical examination in most patients immediately after biopsy, routine chest radiographs were not ordered so long as the patient's vital signs and general condition remained stable. Only one patient, who developed brisk haemoptysis immediately after biopsy, had a chest radiograph. She lost about $200 \mathrm{ml}$ of clotted blood. Her chest radiograph showed no pneumothorax. Her clinical condition and her vital signs remained unchanged. The whole episode resolved without any therapeutic intervention. Her lung biopsy material showed pulmonary fibrosis. In retrospect, she showed features of chronic cor pulmonale and her chest radiograph showed diffuse pulmonary fibrosis with cardiomegaly and prominent pulmonary arteries. She had a packed cell volume of 0.65 . Some patients complained of pleuritic pain but in only two was it severe enough to require analgesics The five patients in whom tuberculosis was diagnosed unequivocally by histological examination had had at least two negative sputum smears each, and in one case sputum was negative on culture.

\section{Discussion}

Table 2 compares the results of trephine biopsy in different studies. There were no deaths in any of the studies and all of the complications were managed easily; the most common complication was pneumothorax. The diagnostic yield ranged from $52 \%$ to $90 \%$.

With a diagnostic yield of $49 \%$ therefore this study has produced the lowest reported yield with the trephine lung biopsy. The three trephines used were new and there was no wobble or premature detachment of the trephine during biopsy that could have accounted 
Table 2 Results of trephine biopsy of the lung in different studies

\begin{tabular}{|c|c|c|c|c|c|}
\hline \multirow[b]{2}{*}{ Authors } & \multicolumn{2}{|l|}{ Biopsy } & \multicolumn{2}{|c|}{ Complications (No (\%)) } & \multirow[b]{2}{*}{ Comments } \\
\hline & Total No & $\begin{array}{l}\text { No }(\%) \\
\text { diagnostic }\end{array}$ & Pneumothorax & Haemoptysis & \\
\hline Steel and Winstanley $(1969)^{1}$ & 119 & $101(85)$ & $31(26)$ & $14(12)$ & $\begin{array}{l}2 \text { pneumothoraces required tube; } 1 \\
\text { haemoptysis of } 50 \mathrm{ml} ; 1 \text { intrapleural blee } \\
\text { of } 150 \mathrm{ml} \text {. Total No of patients not given }\end{array}$ \\
\hline Hendrick and Cowie $(1976)^{4}$ & $\begin{array}{l}\text { (1) } 27 \\
\text { (2) } 20\end{array}$ & $\begin{array}{l}14(52) \\
18(90)\end{array}$ & $\overline{7}(35)$ & - & $\begin{array}{l}\text { (1) used original Steel trephine } \\
\text { (2) used modified Steel trephine. } 3 \\
\text { pneumothoraces needed tube. Total No } \\
\text { of patients not given }\end{array}$ \\
\hline Zavala et al $(1972)^{2}$ & 50 & $42(84)$ & $16(32)$ & $4(8)$ & $\begin{array}{l}7 \text { pneumothoraces needed tube (total } \\
\text { patients 47) }\end{array}$ \\
\hline Cunningham et al (1977) ${ }^{11}$ & 17 & $14(82)$ & $10(60)$ & $3(18)$ & $\begin{array}{l}\text { No of patients not given; all } \\
\text { immunosuppressed } \\
2 \text { haemoptysis required blood } \\
\text { transfusion; } \\
\text { some pneumothoraces needed tube }\end{array}$ \\
\hline Current study & 51 & $25(49)$ & - & $1(2)$ & $\begin{array}{l}39 \text { patients and } 8 \text { necropsies. No chest tubes } \\
\text { needed. Haemoptysis resolved without } \\
\text { treatment. }\end{array}$ \\
\hline
\end{tabular}

for the low yield, as has been suggested previously. ${ }^{4}$ Conceivably, however, lack of fluoroscopic guidance during biopsy and unavailability of mycobacterial culture facilities account in part for the relatively low yield. In a developing country like Ethiopia detection of only five cases of tuberculosis is surprising. Roy and Mahorta ${ }^{3}$ from India reported that almost a third of their patients examined by trephine biopsy had tuberculosis. They reported 60 patients with diffuse and 20 with localised disease with an equal rate of diagnosis of tuberculosis in the two groups. Although they mentioned that they sent half of the tissue for histological studies and the rest for mycobacterial culture, they did not mention how many of the cases were found to be positive for tuberculosis on bacteriological grounds only.

Biopsy specimens from solid masses were much larger than those obtained in diffuse lung diseases. In patients with diffuse pulmonary infiltrates it was discovered fortuitously that biopsy from the inferior lung while the patient was in the lateral decubitus position gave good sized samples. This may be because the inferior lung in the decubitus position is more compressed.

Routine chest radiography after biopsy adds unnecessary expense and exposes the patient to unnecessary radiation. In a country such as Ethiopia, where there is frequently a shortage of radiographic film, radiography after biopsy would be a luxury. Furthermore, the need to treat a pneumothorax by intubation is still controversial. Ruckley and McCormack $^{12}$ recommend chest tubes in pneumothoraces of $20 \%$ or more of cases, while Stradling and Prob $^{13}$ advocate a more conservative approach. At Tikur Anbessa Hospital, where the biopsies were performed, we have to improvise chest tubes and drainage bottles from intravenous giving sets and empty intravenous fluid bags. This kind of practice् increases the risk of infecting the pleural space. IIP these circumstances the only important indication fof a chest tube is not the extent of the pneumothorax buk clinical deterioration of the patient resulting from it

Liver tissue was obtained in five biopsy attempt and in one case lung tissue was obtained simulta $\mathbb{Q}$ neously. This form of double biopsy has not been reported by others. ${ }^{21011}$ Although the approach has always been via the 8th or 9th intercostal space pos= teriorly, it is conceivable that the trephine went through lung tissue and then obtained a core of liver

The only important complication encountered was serious haemoptysis in a woman with pulmonary fibrosis and chronic cor pulmonale. The usuat contraindications reported include bullae, cysts 3 . aneurysms, a bleeding diathesis, respirator 8 insufficiency, poor cooperation by the patient, severe asthma, a recent myocardial infarction, and serious arrythmias. ${ }^{1311}$ From the current experience cors pulmonale would seem to be a risk factor fo․ㅡㅡ. haemoptysis.

The biopsy result definitely altered management in six patients and possibly altered management in eigh $\tilde{S}$ others. Two patients with negative smears and les\$ common radiographic features of tuberculosis wer@ proved to have tuberculosis by biopsy. Three patientso who were having antituberculous treatment becaus of a clinical diagnosis of tuberculosis showed an unsatisfactory response. Two had bronchogenic car=0 cinoma and one had an infected hydatid cyst diag nosed by biopsy. The sixth patient would haves undergone thoracotomy if thick pus had not beer $\vec{B}$ obtained when biopsy was attempted. In this patiento several needle aspirations of the localised mass had 
failed to obtain fluid. The other eight patients could have been given a therapeutic trial for tuberculosis had the trephine biopsy not led to an alternative diagnosis.

\section{References}

1 Steel SJ, Winstanley DP. Trephine biopsy of the lung and pleura. Thorax 1969;24:576-84.

2 Zavala DC, Bedell GN, Rossi NP. Trephine lung biopsy with a high-speed drill: results of 50 biopsies in 47 patients. J Thorac Cardiovasc Surg 1972;64:220-8.

3 Roy DC, Mahorta ML. An evaluation of percutaneous trephine biopsy in the diagnosis of lung diseases. $\mathrm{Am}$ Rev Respir Dis 1979;110:133-6.

4 Hendrick DJ, Cowie J. Percutaneous lung biopsy. Lancet 1976;i:816.

5 Ellis F. Needle biopsy in the clinical diagnosis of tumours. Br J Surg 1974;34:240-4.
6 Sabour MS, Osman LM, Le Golvan PC, Ishak KG. Needle biopsy of the lung. Lancet 1960;ii:182.

7 Manferedi F, Rosenbaum D, Rehnke RH. Percutaneous needle biopsy of the lung in diffuse pulmonary diseases. Ann Intern Med 1963;58:773-7.

8 Smith WG. Needle biopsy of the lung. Lancet 1964;ii:318.

9 Harrison BDW, Thorpe RS, Kitchener PG, McCann BG, Pilling JR. Percutaneous Trucut lung biopsy in the diagnosis of localised pulmonary lesions. Thorax 1984;39:493-9.

10 Stradling P, Prob G. Conservative management of pneumothorax. Thorax 1969;21:145-9.

11 Cunningham JH, Zavala DC, Corry RJ, Kreim LW. Trephine air drill, bronchial brush, and fibreoptic transbronchial lung biopsies in immunosuppressed patients. Am Rev Respir Dis 1977;115:213-20.

12 Steel JS. Lung biopsy with the high-speed drill. $\mathrm{Br} J$ Hosp Med 1972;7:735-8.

13 Ruckley CV, McCormack RMJ. The management of pneumothorax. Thorax 1966;21:139-44. 